\title{
El área léxica de la edad en las ciudades de Sevilla y Méjico D. F.
}

Julia Laguillo Cadenas

\section{Introducción: objetivo del trabajo}

El presente artículo tiene como objetivo describir los usos y valores que los hablantes del nivel popular de ambas ciudades, Sevilla y Méjico D.F., otorgan a los términos que designan el área léxica de la edad ${ }^{1}$.

Para ello, hemos distinguido las cuatro edades o etapas que delimitan la vida del hombre: infancia juventud, madurez y vejez.

Al centramos en cada una de ellas, destacamos, en primer lugar, los valores semánticos que la lengua estándar asigna a los términos particulares, para pasar, en un segundo apartado, al estudio concretamente semántico y sociolingüístico de los diferentes usos por parte de los hablantes.

Es frecuente la adecuación entre la norma lingüística estándar y los valores empleados; pero en otras ocasiones, observamos una discrepancia evidente. En estos casos de no adecuación con la norma (que son los que más resaltaremos), intentaremos analizar los diversos motivos de índole sociológica relacionados con el hablante y su entorno.

Observamos también algunos contrastes entre ambas normas lingüísticas; por una parte, el empleo de términos distintos (los americanimos en Méjico, por ejemplo), por otra, la particular utilización de algunos términos en contextos desconocidos para la norma de la otra ciudad. Asimismo, encontramos algunos casos de total correspondencia entre los usos léxicos de las dos ciudades, junto a la influencia manifiesta de la norma sevillana en la mejicana.

Este trabajo no pretende abarcar la totalidad de los términos existentes ni de los usos particulares que pueden aparecer en ambas ciudades, debido, entre otras cosas a la

${ }^{1}$ Vid. nota 1 en Apéndice de Notas. 
limitación del corpus; sin embargo, creemos que el estudio es significativo, ya que siendo un trabajo basado en las encuestas debe recoger los términos más relevantes.

Por otra parte, deseamos hacer constar que el presente artículo tiene, igualmente, la intención de subsanar las erratas de imprenta y composición aparecidas en nuestro artículo «El Español de Andalucía y América: una aproximación léxica», en Sociolingüística Andaluza, vol. V, publicaciones de la Universidad de Sevilla, 1990, así como matizar algunas de las afirmaciones referentes al apartado de la edad madura.

\section{Edad infantil}

\section{1. Corpus de investigación: corpus léxico de las ciudades de Sevilla y Méjico}

Centrándonos en el léxico de la edad infantil, hay que subrayar, en primer lugar, qué entiende el Diccionario de la R.A.E. (DRAE a partir de ahora) por infancia ${ }^{2}$.

Infancia (del latín 'infantia') f. periodo de la vida del niño desde que nace hasta los comienzos de la pubertad.

El término 'niñez' es recogido en el DRAE con un significado similar: Niñez (de niño) f. periodo de la vida humana que se extiende desde el nacimiento hasta la adolescencia.

Para designar a una persona que se halla en esta edad, el término más general y estándar es 'niño':

Niño (de la voz infantil 'ninno') adj., que se halla en la niñez (u.t.c.s.). 2. Por extensión, que tiene pocos años (u.t.c.s.).

8. fig., en el trato afectivo, persona que ha pasado de la niñez. U. más en vocativo. 9. m. y f. Andalucía y Canarias: persona soltera, aunque tenga muchos años.

Sin embargo, en el cómputo analizado de ambas ciudades, aparecen otros términos que igualmente se refieren a este período de la vida humana:

Criatura (del latín 'creatura') f. toda cosa criada. 2 . Niño recién nacido o de poco tiempo. 3. Foto antes de nacer.

«Ser uno una criatura»: fr. fig., fam. ser de muy poca edad. 2. Fig. y fam., tener propiedades de niño.

Crio-a (de criar) m. y f. niño o niña que se está criando. 2. Por extensión, persona joven relativamente a otra.

Pequeño-a (creac. expresiva como port. 'pequeño' y ant. sardo 'pikinnu') adj. corto y limitado. 2. De muy corta edad.

Chico-a (del latín 'ciccum', cosa de poquísimo valor) adj. pequeño o de poco tamaño. 2. Niño (u.t.c.s.). 3. Muchacho (u.t.c.s.). 7. Hombre o mujer sin especificar la edad cuando ésta no es muy avanzada. 8. Tratamiento. U. fam. en lenguaje coloquial.

Chiquillo-a (d. de chico) adj. chico, niño, muchacho (u.t.c.s.)

${ }^{2}$ Vid. bibliografía (IX). 
Muchacho-a (de mochacho) $\mathrm{m}$. y f., niño o niña que no ha llegado a la adolescencia. 2. Niño o niña que mama. 4. Fam., persona que se halla en la mocedad.

Chaval-a (del gitano 'chavale', voc. plur. de chavó, muchacho) m. y f., popularmente, niño o joven. (ú. menos como adjetivo).

Chavó-á. Germ. chaval

Otros términos que aparecen en las encuestas no se hallan recogidos en el DRAE, por lo que recurrimos al Diccionario de Santamaría ${ }^{3}$ :

Escuincle-a (del azteca 'itzcuintli', perro), despec., fam., perro ordinario, callejero. 2. por extensión, se aplica también a personas, especialmente a los niños; rapaz.

Chamaco-a (del azteca 'chamaua', engruesar, o 'chamaual', grueso) m. y f. voz genérica usada comúnmente en Méjico y, por extensión, en Centroamérica y otras partes de América por muchacho, niño pequeño o hasta antes de la pubertad. 2. En sentido afectivo y cariñoso se dice de persona joven o de apariencia muy joven.

\section{2. Análisis semántico contextual y sociolingüístico del corpus léxico}

Una vez conocido el corpus léxico con el que vamos a trabajar, veamos los diferentes usos contextuales y posibles implicaciones sociolingüísticas que nos pueden sugerir.

\section{II.2.1. NIÑO-A}

Por lo general, este término suele responder a su acepción primera y, por extensión, a la segunda (vid. II. 1), como observamos a continuación ${ }^{4}$ :

1. En primer lugar destacamos aquellas ocasiones en que el término «niño» hace referencia a la edad infantil de una manera general, sin especificar relaciones personales. Por ejemplo, en Sevilla: enc. IV. pág. 101: «la clase de las niñas» ${ }^{5}$.

2. Sin embargo, es más interesante observar el uso del término en contextos donde apreciamos una relación de parentesco familiar o de otro tipo igualmente afectivo, entre el informante y la persona designada. Son numerosos los ejemplos en los que 'niño' equivale a «hijo pequeño». Por citar uno, el de la enc. XI. pág. 265: «mis niños», de Sevilla ${ }^{6}$.

En algunos casos el término sirve para especificar el sexo de los hijos más que la edad en sí; en Sevilla: enc. X, pág. 33: «no me preocupan que sean niñas porque para mí lo mismo es la mujer que el hombre». En Méjico: m. XIV, pág. 184; m. XXIII, pág. 320 .

\footnotetext{
${ }^{3}$ Vid. bibliografía.

${ }^{4}$ Vid. nota 2, apéndice de notas.

${ }^{5}$ Vid. nota 3.

${ }^{6}$ Vid. nota 4.
} 
Otras veces, el término indica una relación de parentesco familiar diferente, la de hermano pequeño ${ }^{7}$.

Para especificar la referencia a los primeros años de la infancia observamos en Méjico la ayuda del diminutivo: m. XXIII, pág. 177: «una niñita» (de un mes).

El DRAE nos ofrece otra acepción interesante que figura con el número 9: "persona soltera aunque tenga muchos años», la cual aparece como un uso andaluz; sin embargo, en las encuestas el término llega a extenderse al ámbito de la juventud, más estricto, por tanto, que el que recoge la acepción: enc. VI, pág. 146: «había dos niñas» (oficinistas) $^{8}$.

En Méjico suele ser aún más restringida la aplicación del término, no extendiéndose más allá de la adolescencia? .

Por último, destacamos algunos ejemplos que podrían responder a la acepción 8. del DRAE, de uso vocativo, (vid. II.1). En Sevilla: enc. XXIV pág. 540; en Méjico: $m$. XV, pág. 208. término:

Veamos a continuación en un gráfico el porcentaje de los diferentes valores del

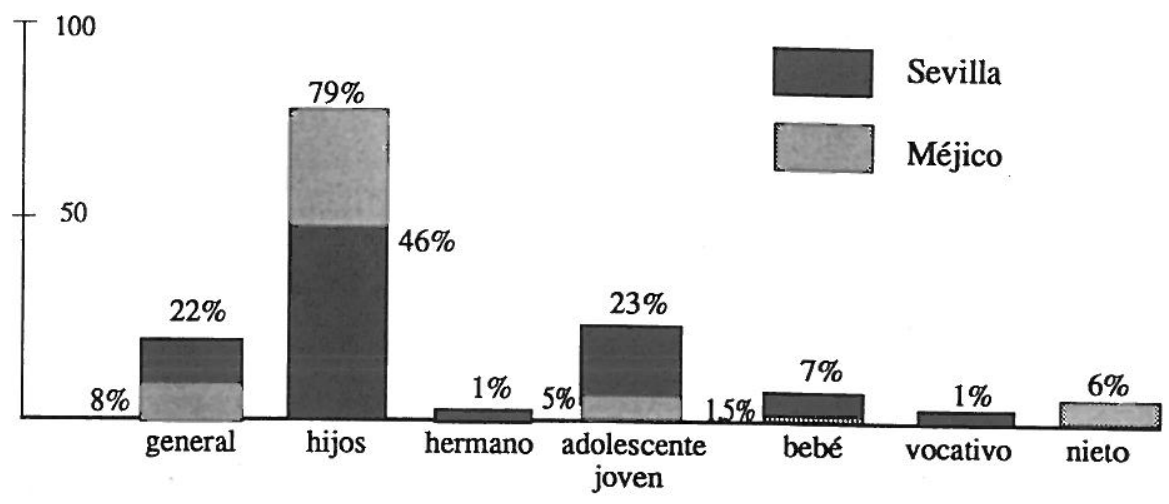

En relación con Méjico, destacamos el alto porcentaje del valor equivalente a «hijo», así como el de «nieto», no recogido en Sevilla debido a las particulares situaciones familiares, diferentes en una y otra ciudad. Es también interesante resaltar la menor aplicación del término para referirse a un adolescente o a un joven, respecto a Sevilla.

\footnotetext{
${ }^{7}$ Vid. nota 5.

${ }^{8}$ Vid. nota

${ }^{9}$ Vid. nota 7 .
} 


\section{II.2.2. CRIATURA}

Este término nos presenta valoraciones subjetivas interesantes por parte de los hablantes. La acepción primera del DRAE es tan general, que podemos decir que siempre se cumple (vid. II.1.)

En cuanto a la acepción 2., encontramos casos de referencia a niños pequeños, pero no «recien nacido»: Sevilla: en, XVII, pág. 411; en Méjico: m. XIX, pág. 266.

Sin embargo, destacamos un hecho palpable en muchos ejemplos: criatura suele presentar una connotación de lástima equivaliendo a «ser indefenso». Asípueden recibir tal denominación personas de cualquier edad, no sólo los niños. Por ejemplo, en Sevilla: enc. IX, pág. 214: «montones de criaturas que están igual» (personas en situación de paro $)^{10}$.

Este último valor, tan común en ambas ciudades, no se especifica en el DRAE.

\section{II.2.3. CRIO-A}

Término sólo documentado en Sevilla. De la primera acepción del DRAE (vid. II.1) podemos deducir un valor general: «niño o niña que se está criando», es decir, un niño más bien pequeño, como observamos en: enc. XV. pág. 348 y enc. VI, pág. 151.

Sin embargo, es frecuente que el término presente connotaciones semejantes a las que hemos visto en 'criatura': "niño indefenso o inocente» enc. XV. pág. 351: «yo creo que este crío ni se concentra en sus estudios ni nada» (cualquier niño cuyos padres se divorcian) ${ }^{11}$.

El DRAE nos ofrece una segunda acepción (vid. II.1), que podría ser el caso de: enc. III, pág. 74: «mucho crío, que más que porque fueran críos. . . (en un contexto de costaleros, son demasiados jóvenes para hacerlo bien).

\section{II.2.4. PEQUEÑO-A}

Término recogido únicamente en Sevilla, al igual que el anterior, aunque de uso no muy extendido entre los hablantes si lo comparamos con 'chico', de valor muy semejante y que trataremos a continuación.

1. De su valor originario, se extiende la noción de "persona de muy corta edad» (vid. II. 1), siempre como adjetivo aunque puede aparecer sustantivado: enc. IV, pág. 101: «cuando yo era pequeño» ${ }^{12}$.

2. Puede, así mismo, aparecer en construciones comparativas frente al término «mayon»: enc. XII, pág. 301: «la mayor tiene tres años. . . la pequeña. . .».

\footnotetext{
${ }^{10}$ Vid. nota 8.

11 Vid. nota 9.

${ }^{12}$ Vid. nota 10.
} 


\section{II.2.5. CHICO-A}

El DRAE nos ofrece, en primer lugar, una acepción que identifica a 'chico' con 'pequeño' (vid, II,1). Esto referido a las personas origina las acepciones 2. y 3.: niño, muchacho.

1. En primer lugar, nos centraremos en las referencias a la niñez conuso de adjetivo calificativo, con valor positivo, aunque aparezca sustantivado: Sevilla: enc. I, pág. 39; Méjico: m. VI, pág. 87.

Resaltaremos el empleo de chico como especificador de la primera etapa de la infancia acompañando al término 'niño'; en Sevilla: enc. XIV, pág. 325: «con el niño chico»; en Méjico: m. VII, pág. 112.

La misma función cumple yendo en diminutivo, uso recogido en ambas ciudades aunque es especialmente relevante en Méjico: m. XXXIII, pág. 435: «la niña chiquita» (de tres meses). En Sevilla: enc. VIII, pág. 191.

2. Otras veces, el término 'chico' se refiere a un concepto de «niño» con un uso sustantivado, no calificativo. Es patente sobretodo en Méjico: m. XXVII, pág. 356, «tiene dos chiquitas»; m. XXVIII, pág. 380.

3. En ocasiones, los hablantes hacen valoraciones subjetivas al aplicar el término: por ejemplo la muestra XIII de Méjico, pág. 179: «Se casó bien chica» (16 años) ${ }^{13}$.

4. 'Chico' además puede aparecer en construcciones comparativas funcionando por oposición a otras expresiones como «el mayon, «el grande», bien presentes, bien sobreentendidas en el contexto: m. III, p. 51: «la más chica» ${ }^{14}$.

En Sevilla hay ejemplos que podríamos incluir en el apartado 7. del DRAE (vid. II.1); sin embargo en las encuestas se hace referencia concretamente a jóvenes, por lo que se trataría de un uso más restringido que el que recoge esta acepción del DRAE. enc. V, pág. 126: «eso le pasó una vez a una chica» (alumna joven) ${ }^{15}$. No hemos hallado ningún caso similar en Méjico.

Dentro del valor equivalente a "pequeño», es interesante diferenciar los grados comparativo y positivo. Según las encuestas, los hablantes de una y otra ciudad los emplean en estas proporciones:

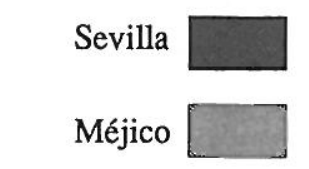

${ }^{13}$ Vid. nota 11.

${ }^{14}$ Vid. nota 12.

15 Vid. nota 13.

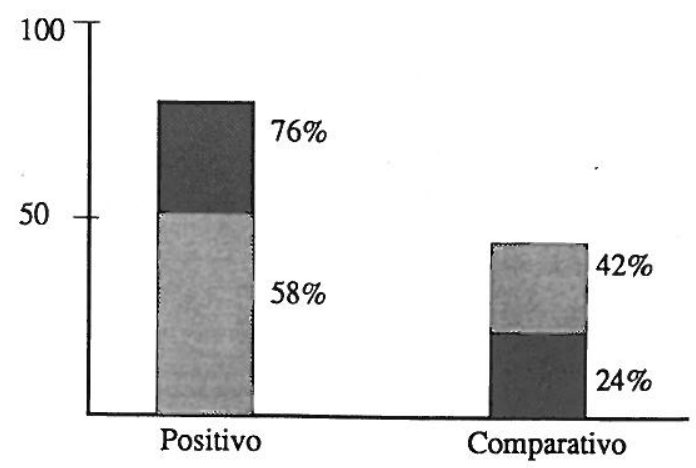


Es importante destacar el alto porcentaje del valor comparativo en Méjico respecto a Sevilla. Ello se debe a que el término se emplea muy frecuentemente en construcciones comparativas aplicándose incluso a personas ya alejadas de la niñez.

\section{II.2.6. CHIQUILLO-A}

Por lo general los usos responden a las acepciones del Diccionario: «niño», «muchacho», (vid, II, 1), aunque a veces encontramos valoraciones subjetivas. A pesar de que el DRAE le asigne un valor adjetivo es más frecuente su sustantivación.

1. Son frecuentes los ejemplos en que equivale simplemente a «niño», sobre todo en Méjico: m. XIX, pág. 269: «todos son chiquillos» ${ }^{16}$.

2. Observamos que en Méjico al término 'chiquillo' puede aparecer en construcciones comparativas; este uso es desconocido en Sevilla: m. XXXIV, pág. 451: «el más chiquillo».

En general, podemos decir que el término se adapta a la acepción del DRAE (usualmente como sustantivo), con un valor connotativo peculiar de cariño o afecto.

Veamos ahora el porcentaje con que el término aparece en las encuestas según la edad y sexo de los informantes:
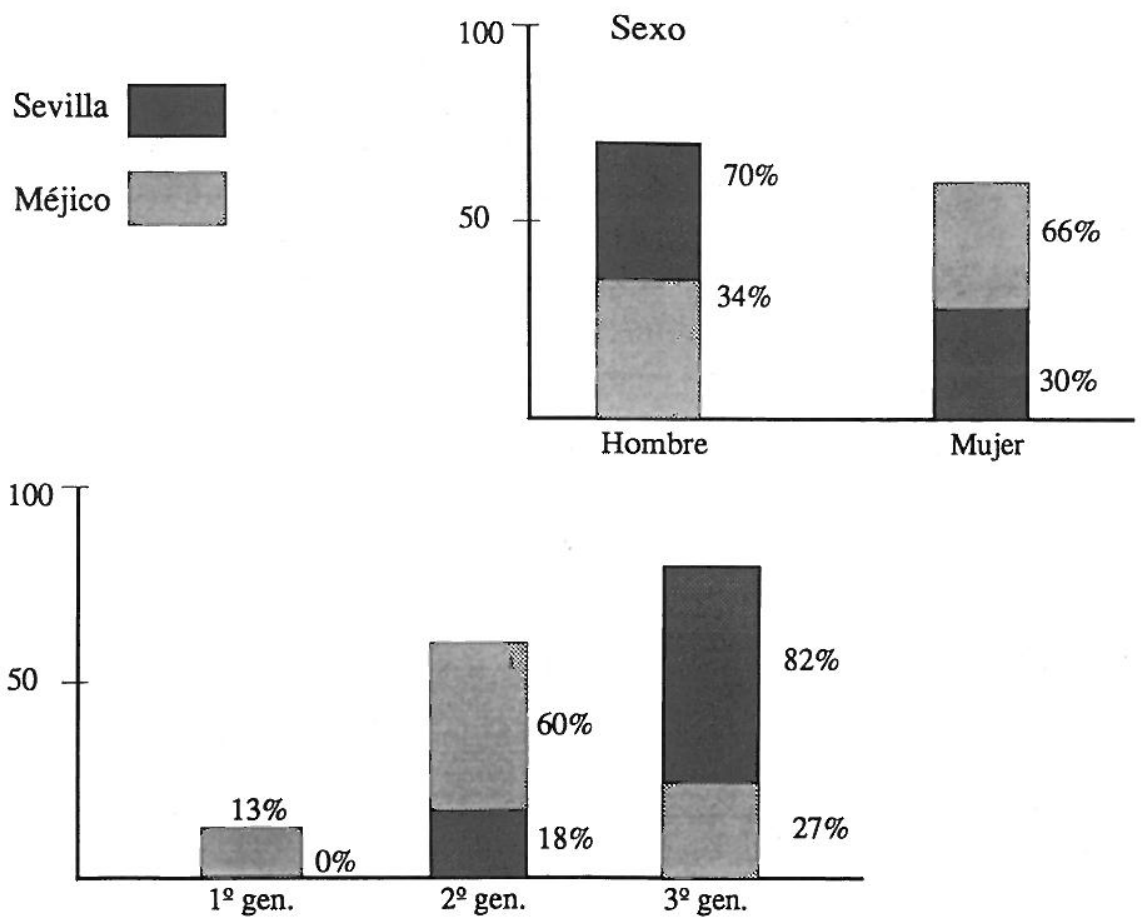
Según las encuestas, en Sevilla el término 'chiquillo' es usado mayoritariamente por los varones de más de 45 años, y hoy día está en desuso entre los jóvenes. En cạmbio, en Méjico los hablantes que más emplean el término son las mujeres de edad comprendida entre los 35 y 54 años. Es posible que en este comportamiento peculiarmente diferente en una y otra ciudad influya el hecho de que los hombres mejicanos de esta edad parecen preferir otros términos, como por ejemplo 'chamaco' (americanismo que trataremos más adelante).

\section{II.2.7. MUCHACHO-A}

En ambas ciudades, el término 'muchacho' suele hacer referencia a la edad juvenil, aunque pueden documentarse algunos ejemplos que responden al valor etimológico original (vid. II.1).

En Sevilla sólo aparece un caso, en la enc. XVIII, pág. 404: «ese día no tuvo el muchacho bastante fuerza».

En Méjico los ejemplos son más numerosos: m. XIV, pág. 188: «el problema de los muchachos tan chicos» (edad de Primaria) ${ }^{17}$.

\section{II.2.8. CHAMACO-A}

Como hemos visto en el apartado del corpus léxico (vid. II.1), 'chamaco' es un americanismo que puede hacer referencia tanto a la infancia como a la juventud, aunque parece ser que su acepción original es la de «niño pequeño». En el uso infantil que nos ocupa encontramos algunos ejemplos; citemos alguno: m. XVI, pág. 85: «cuando yo era chamaco» ${ }^{18}$.

Dos gráficos nos pueden ilustrar a continuación la incidencia de la edad y sexo de los informantes en el uso del término:
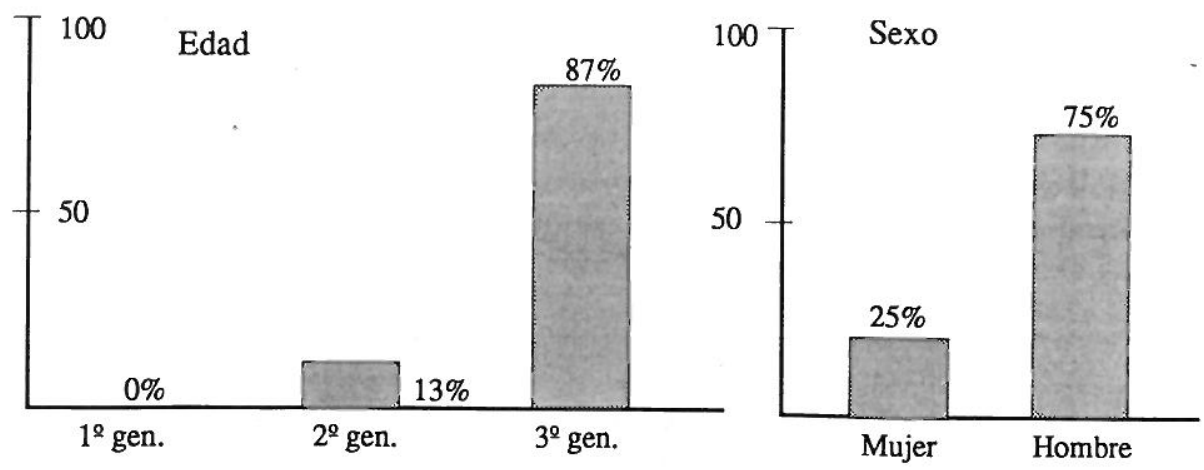

${ }^{17}$ Vid. nota 15.
${ }^{18}$ Vid. nota 16. 
De este gráfico puede deducirse que 'chamaco', refiriéndose a la edad infantil, es empleado, sobre todo, por los hombres de la $3^{\mathrm{a}}$ generación (vid. II.2.6).

\section{II.2.9. ESCUINCLE-A}

Americanismo recogido en Méjico. Sabemos que de su acepción original («perro callejero»), dicho término ha tomado el valor de «muchacho, niño, rapaz». Este es el significado que aparece en los ejemplo siguientes: m. III, pág. 49: «parecía un escuincle» (niño m. IV, pág. 60.

Una vez analizado el corpus léxico de la edad infantil, observemos en un gráfico comparativo el porcentaje respectivo de los términos:

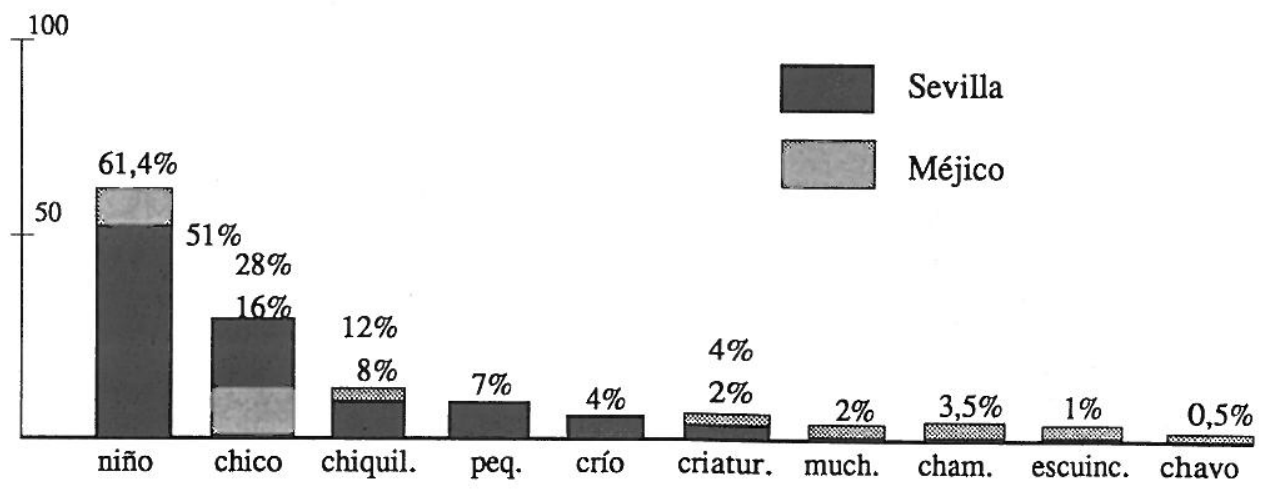

Es relevante el menor porcentaje de empleo del término 'chico' en Méjico respecto a Sevilla; esto se debe, posiblemente, a que en aquella ciudad se usa mucho con valor comparativo, aunque no haga referencia a la edad infantil.

\section{Edad juvenil}

\section{III.1. Corpus de investigación: corpus léxico de las ciudades de Sevilla y Méjico}

En primer lugar, trataremos de delimitar el área de la edad juvenil según lo entiende el DRAE:

Juventud (del latín 'iuventis-atis') f., edad que empieza en la pubertad y se extiende a los comienzos de la edad adulta.

Los téminos comunes para designar a una persona de esta edad son:

Joven (del latín 'iuvenis') adj., de poco valor. 3. (com.) persona que está en la juventud. 
Muchacho-a (vid. II.1)

Chaval-a (vid. II.1)

En Méjico aparecen términos no recogidos en Sevilla:

Chavo-a: germ. chaval.

Pollo (del latín 'pollus')m. cría que sacan de cada huevo las aves, y particularmente las gallinas; 7. fig. y fam., joven; 8. fig. y fam., hombre astuto y sagaz.

Chamaco-a (vid. I.1)

\section{2. Análisis semántico contextual y sociolingüístico del corpus léxico}

\section{III.2.1. JOVEN}

Como acabamos de observar, el término que nos ocupa es el más común para designar a una persona que se halla en la juventud; sin embargo, en el ámbito de esta edad influyen de manera determinante las valoraciones subjetivas del hablante, producidas, posiblemente, por la realidad concreta de su edad y otras circunstancias personales.

1. Dentro de este campo algo difuso de la juventud observamos numerosos ejemplos que responden al concepto general de ésta ${ }^{19}$.

2. Sin embargo, son más interesantes las valoraciones subjetivas por parte de los informantes; en Sevilla, en ocasiones se asigna el término a una persona cercana a la madurez: enc. XVI, pág. 367 «el sevillano joven» (hace referencia a que tenga menos de 45 años) ${ }^{20}$. En Méjico, en cambio, el término designa una juventud amplia (hasta unos 30 años), pero no llega a identificarse con la madurez: m. XIII, pág. 170; m. XXX, pág. 409. Incluso en ocasiones, observamos que se usa para referirse a un adolescente: $\mathrm{m}$. IV, pág. 57: «cuando uno es joven no se quiere a esos viejos» (habla de una edad temprana, 13 o 14 años $)^{21}$.

3. Con frecuencia, como ocurría con 'chico', se establecen contrastes y comparaciones. En cuanto a los contrastes, lo observamos en ambas ciudades; en Méjico: «mis hermanas ya estaban jovencitas, ya no eran chiquitas». En Sevilla: «los jóvenes» (en oposición a «gente mayor»), en la enc. V, pág. 134.

Sin embargo, las construcciones comparativas con el término 'joven' solo aparecen en Sevilla: enc. VIII, pág. 197: «la más joven (. . . la más vieja». El hablante mejicano en estas ocasiones, tiende a emplear el término 'chico' aunque se refiera a personas de edad avanzada (vid. II.2.5).

Nos interesa contrastar los valores de 'joven' en Méjico, destacando únicamente las ocasiones en que los informantes usan el término con el valor usual de juventud y aquellas otras en las que se hace referencia a la adolescencia:

\footnotetext{
19 Vid. nota 17.

${ }^{20}$ Vid. nota 18.

${ }^{21}$ Vid. nota 19.
} 


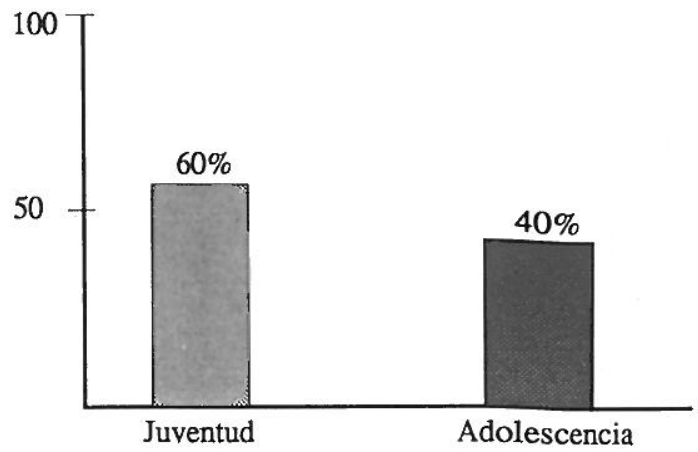

La asignación del término 'joven' para los adolescentes es de importancia notable, demuestra, en definitiva, una tendencia del hablante mejicano a anticipar las denominaciones de las diferentes edades.

\section{2.2. MUCHACHO-A}

Como observamos en el apartado de la edad infantil, actualmente el término 'muchacho' suele emplearse para designar a una persona joven. Este es el valor general en ambas ciudades y no vamos a insistir poniendo ejemplos en que la referencia a un joven es evidente.

Nos centraremos en los usos que presentan un claro valor subjetivo por parte del hablante. Ya hemos tratado la referencia a la edad infantil en su apartado correspondiente (vid. II.2.7); vemos ahora aquellos casos en que 'muchacho' designa a una persona que, en sentido estricto, ya no es joven y entronca con la madurez; en Sevilla: enc. XIII, pág. 337: «el muchacho no era malo (hombre de unos 45 años). En Méjico: m. XIII, pág. 169: «la muchacha» (hija de 35 años) ${ }^{22}$.

Destacamos un hecho interesante: los hablantes mejicanos usan frecuentemente el término para referirse a los hijos (en una niñez avanzada, adolescencia, e incluso en la juventud), hecho que resulta extraño en Sevilla: m. XIII, pág. 170: «su muchacho grande» (su hijo mayor, de 20 años).

Ilustremos a continuación las diferentes edades que puede designar el término en una y otra ciudad: 


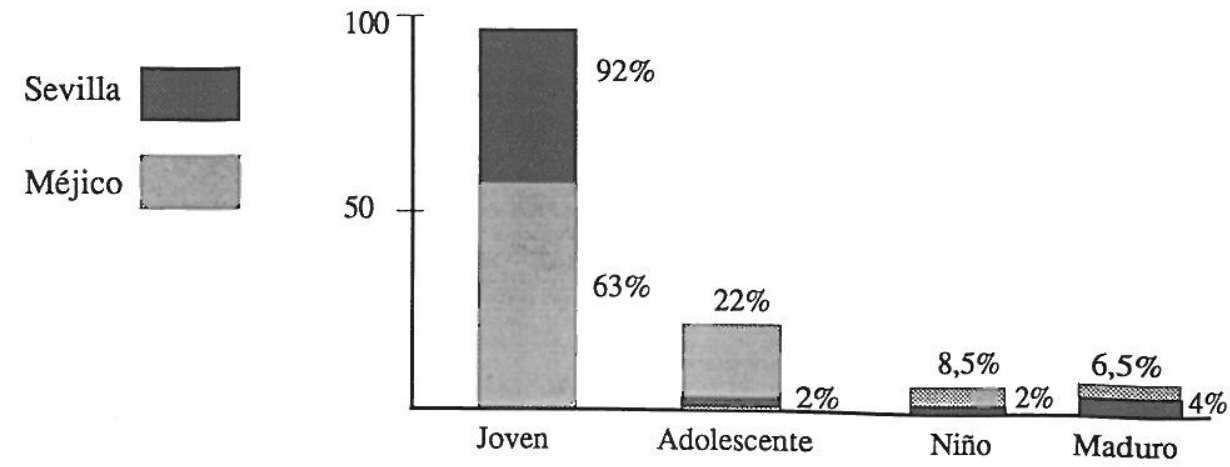

Observamos que en Sevilla el término 'muchacho' presenta un uso bastante acorde a la norma general del español; en cambio, en Méjico, la referencia a la adolescencia y a la niñez representa un porcentaje más elevado respecto a los otros valores que el observado en Sevilla.

\section{2.3. CHAVAL-A}

Término caló recogido únicamente el Sevilla. Como hemos visto anteriormente (v.II.1) 'chaval' puede significar tanto «niño» como «joven» siendo éste último el valor más usual. Por ejemplo: enc. I, págs. 25, 26 y 32; enc. II, pág. 63 y enc. III, pág. 84.

Destacamos un uso peculiar, el de la enc. IX, pág. 212: «pero chavala... chavala no, porque no me gusta estar amarrado», donde el hablante uso el término con el sentido de «acompañante o novia».

Observamos en un gráfico ilustrativo el sexo y generación de los hablantes que más emplean el término:

Edad

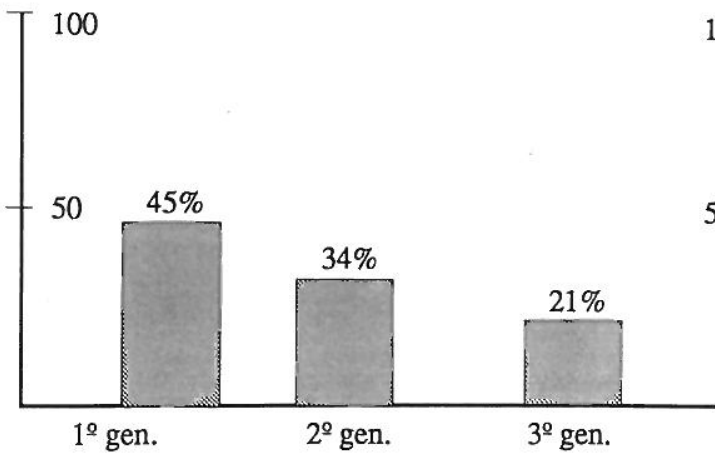

Sexo

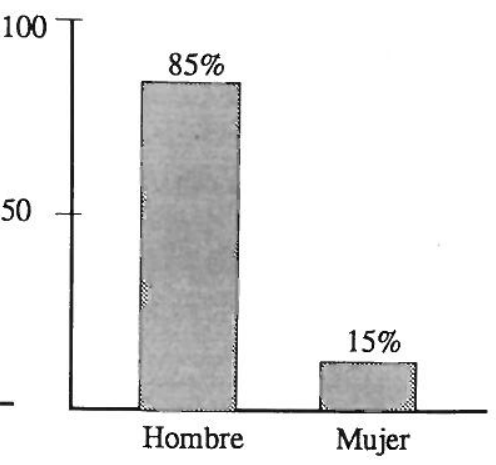


Podemos deducir que 'chaval' es un término usado mayoritariamente por los hombres en las tres generaciones, aunque con predominio en la generación joven, yendo en disminución progresiva en las dos restantes.

\section{2.4. CHAVO-A}

El DRAE recoge el término caló ‘chavó' como sinónimo de 'chaval’ (II. 1).

En cambio, los ejemplos recogidos en las encuestas parecen mostramos el término con acentuación llana. Su empleo, por otra parte, es escaso haciendo siempre referencia a la juventud ${ }^{23}$ : m. XXVIII, pág. 371: «toditas las chavas»; m. XXIV, pág. 328: «platícame algo de tus chavas» (en el sentido de «ligues», valor semejante al que hemos visto en 'chaval'24.

\section{2.5. POLLO}

Tal y como recoge el DRAE (III. 1) este término se puede aplicar a las personas para designar la juventud. Encontramos un único ejemplo y en las encuestas mejicanas: m. XXXI, pág. 421: «usted está pollo todavía (.. .) a los treinta comienza uno a bajan».

\section{Edad madura}

\section{1. Corpus de investigación: corpus léxico de las ciudades de Sevilla y Méjico}

En primer lugar, precisaremos en qué consiste esta edad según el DRAE:

Edad madura: «la comprendida entre los finales de la juventud y los comienzos de la vejez».

Madurez: (de 'maduro') fem., sazón de los frutos. 3. Edad de la persona que ya ha alcanzado su plenitud vial y todavía no ha llegado a la vejez.

Para denominar a una persona que se halla en esta edad no hay un término específico, sino que simplemente utilizamos la designación 'hombre' (o 'mujer' en el caso de sexo femenino). Precisemos los significados de ambos términos:

Hombre (del latín 'homo-nis'). 3. el que ha llegado a la edad viril o adulta.

Mujer (del latín 'mulier-ris') f. persona de sexo femenino. 2. la que ha llegado a la edad de la pubertad. 3. la casada en relación al marido.

El hombre (o mujer) del que tratamos en este apartado es de edad más restringida, iría, aproximadamente de los 35 a los 55 años.

A la hora de calificar con un adjetivo a una persona que se halla en la edad madura, la lengua española nos ofrece dos términos: 'mayor' y 'grande'.

\footnotetext{
${ }^{23}$ Vid. nota 21.

${ }^{24}$ Vid. nota 22.
} 
Mayor (del latín 'maior-ris') adj., comparativo de 'grande', que excede a una cosa en cantidad o calidad. 2 . dícese de la persona que excede en edad a otra. 4. dícese de la persona entrada en años, de edad avanzada.

Grande (del latín 'grandis') adj. que excede en tamaño, importancia, dotes, intensidades, etc., a lo común y regular. 2 . dícese de la persona de edad avanzada.

\section{2. Análisis semántico contextual y sociolingüístico del corpus}

\section{2.1. HOMBRE}

Este término, 'hombre', es el que suele designar a una persona de sexo masculino que ha llegado a la edad adulta. En las encuestas suele aparecer en referencias generales donde no se especifica la edad ${ }^{25}$, aunque a veces el contexto nos permite clasificar la aplicación dentro de la edad madura. Por ejemplo, en Sevilla: enc. III, pág. 93: «este hombre» (alcalde de la ciudad) ${ }^{26}$.

Otras veces, el término se aplica a personas que se hallan en otras edades: en la $v e j e z^{27}$ o en la juventud ${ }^{28}$. Incluso hay un caso en Méjico de referencia a un niño: m. XIX, pág. 265: «los hombrecitos» (sus hijos varones, niños aún, de ahí el diminutivo).

Constatamos otro valor bastante frecuente: 'hombre' como diferenciador de sexo frente a 'mujer'. Por ejemplo, en Méjico: m. XIII, pág. 172: «seis mujeres y cuatro hombres»"

\section{2.2. MUJER}

Al igual que 'hombre', 'mujer' suele aparecer en designaciones generales que no especifican la edad, tanto en Sevilla como en $\mathrm{Méjico}^{30}$. Sin embargo en ocasiones podemos descubrir aproximadamente a qué edad se aplica el término identificándolo con la madurez (Sevilla, enc. XI, pág. 258).

En Méjico el contexto nos permite a veces descubrir que el término se aplica a una adolescente: m. VII, pág. 101: «su muchacha, su mujercita»; o bien incluso a una niña: m. XXX, pág. 409: «son mujercitas» (hijas menores de 7 años). Estos dos últimos casos no resgistrados en Sevilla responden a algo que ya habíamos señalado anteriormente: los mejicanos muestran una tendencia a anticipar las edades mediante el uso del diminutivo; éste no aporta sólo un valor afectivo, sino que tiene una función morfosemántica clara.

\footnotetext{
${ }^{25}$ Vid. nota 23.

${ }^{26}$ Vid. nota 24 .

${ }^{27}$ Vid. nota 25.

${ }^{28}$ Vid. nota 26.

${ }^{29}$ Vid. nota 27.

${ }^{30}$ Vid. nota 28.
} 
Por último destacamos el empleo de 'mujer' como «esposa», frecuente en ambas ciudades, aunque más relevante es Sevilla ${ }^{31}$.

\section{2.3. MAYOR}

En primer lugar, trataremos su acepción original y etimológica de uso comparativo: enc. V, pág. 138: «mi hermano el mayon», de Sevilla ${ }^{32}$.

Centrandonos en el valor que nos interesa, el uso positivo de adjetivo calificativo (acep. 4 del DRAE, vid. IV. 1), observamos lo siguiente:

En Sevilla abundan los casos en que el término hace referencia evidente a la edad madura: enc. VI, pág. 61: «un matrimonio mayor» (de unos 90 años) ${ }^{33}$.

En ocasiones, las valoraciones de los hablantes hacen extender el término hasta lo que consideramos «vejez»: en. XIII, pág. 305: «una mujer ya mayor, con 84 años» ${ }^{34}$; o bien se aplica a un niño para especificar que ya no es pequeño: enc. XV, pág. 346: «la niña es mayor» (13 años $)^{35}$, e incluso, a un joven: enc. XIII, pág. 317: «hijas mayores» (en edad de estar casadas) ${ }^{36}$.

En un gráfico podemos contrastar las diversas edades a las que puede aplicarse es término:

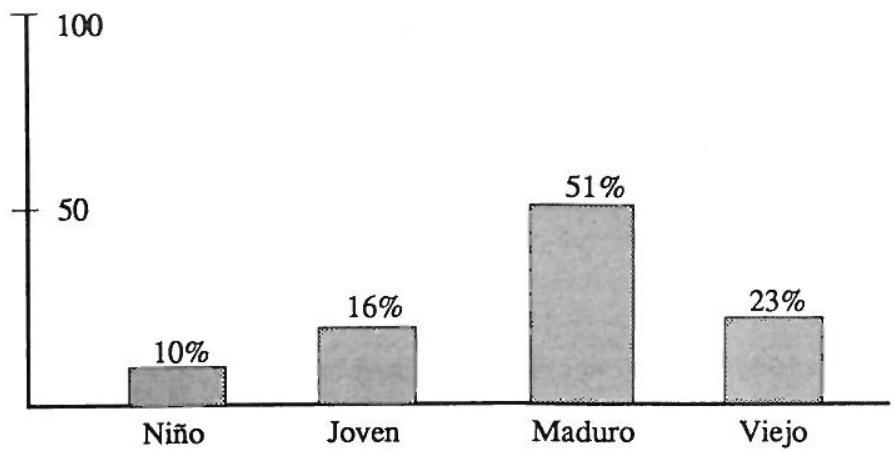

En cambio, en Méjico, tan sólo constatamos un ejemplo y referido a una persona que podemos considerar ya madura: m. XIV, pág. 196.

A continuación cotejemos en un gráfico los dos valores principales asignados al término: el grado positivo y el comparativo:

\footnotetext{
${ }^{31}$ Vid. nota 29.

${ }^{32}$ Vid. nota 30.

${ }^{33}$ Vid. nota 31 .

${ }^{34}$ Vid. nota 32.

35 Vid. nota 33.

${ }^{36}$ Vid. nota 34.
} 


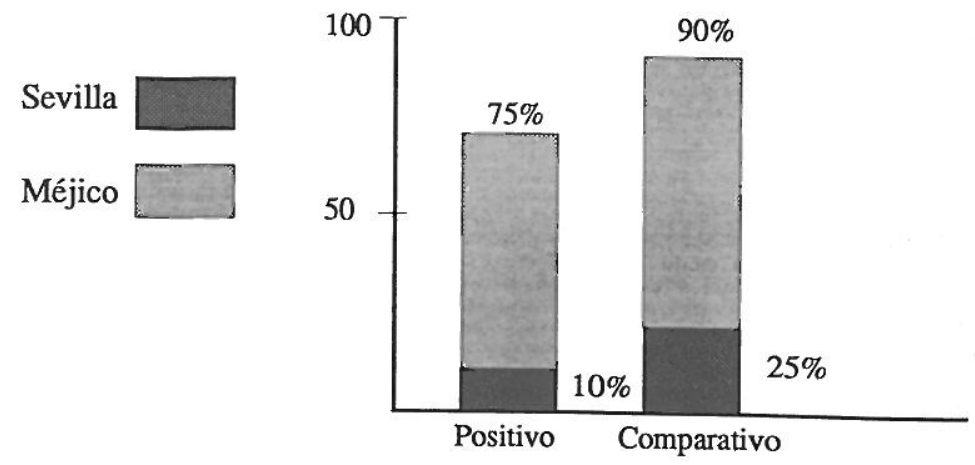

Como podemos observar, ambas ciudades manifiestan un comportamiento muy diferente a la hora de emplear este término.

\section{2.4. GRANDE}

Tal y como recoge el DRAE, 'grande' puede designar a una persona de edad avanzada o madura (IV.1).

EnSevilla, su uso es escaso, si bien algo más frecuente con valor comparativo: enc. XXIV, pág. 337: «con el grande y con el chico» ${ }^{37}$.

En Méjico, en cambio, su empleo es muy común; o bien apareciendo en construcciones comparativas ${ }^{38}$; o bien presentando un valor positivo de «persona de edad avanzada» (vid. IV. 1). Centrándonos en este último valor observamos lo siguiente:

1. Los casos de referencia a una persona en edad madura son los más abundantes: m. XIII, pág. 169: «su muchacha ya está grande» ${ }^{39}$.

2. En ocasiones el término llega a aplicarse a personas que se hallan en la vejez: m. V, pág. 73: «como ya están grandes. .. (no pueden trabajar).

3. Incluso se recoge el uso del término aplicado a niños para recalcar que no son pequeños: $\mathrm{m}$. XXVII: «ya están grandes» (hijos mayores de 12 años) ${ }^{41}$.

4. De igual modo el término se aplica a un joven llevando inherente una oposición a la niñez: m. III, pág. 44: «era para puros grandes» ${ }^{42}$.

A continuación veamos en un gráfico el porcentaje con que aparecen los diferentes valores del término en Ciudad de Méjico:

\footnotetext{
${ }^{37}$ Vid. nota 35 .

${ }^{38}$ Vid. nota 36.

${ }^{39} \mathrm{Vid}$, nota 37.

${ }^{40}$ Vid. nota 38.

${ }^{41}$ Vid. nota 39.

${ }^{42}$ Vid. nota 40.
} 


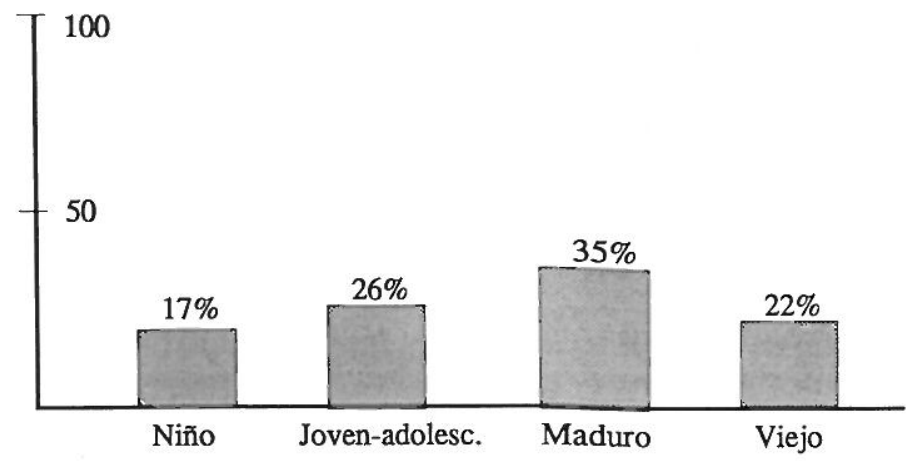

Es también interesante cotejar los dos valores observados en el término: grado positivo y comparativo:

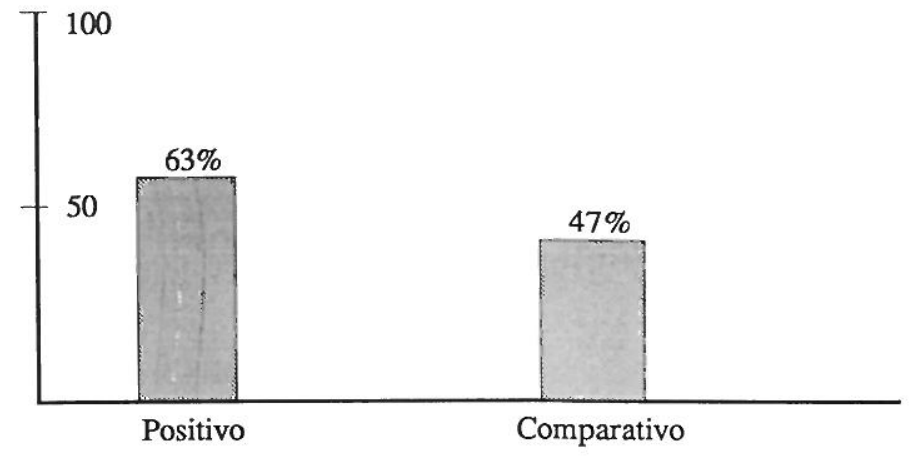

El mayor uso del valor positivo contrasta significativamente con lo que observamos en Sevilla, donde sólo hemos documentado un caso de construcción comparativa.

En cuanto al valor comparativo también 'grande' presenta un uso más extendido que 'mayor', siendo su porcentaje de aparición muy superior al que representa en Sevilla:

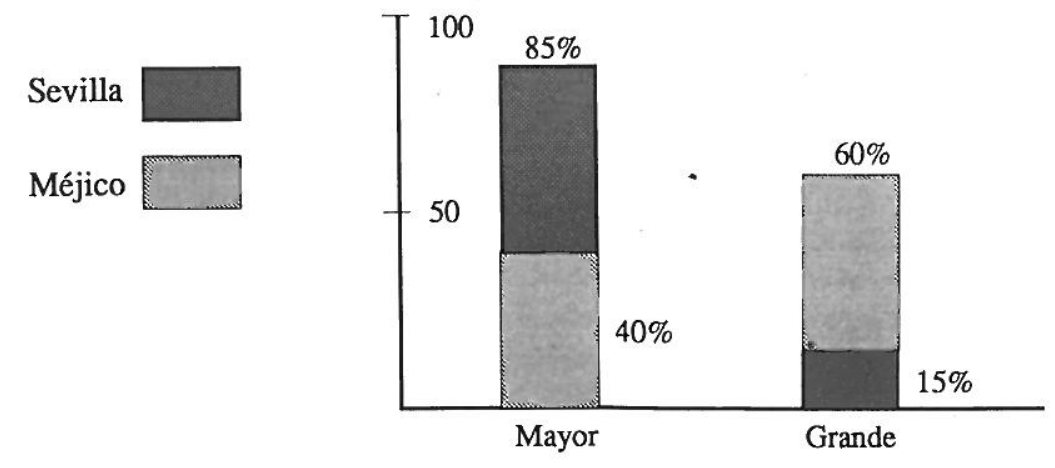


Del estudio comparativo de ambos términos podemos deducir que nos encontramos ante uno de los casos más interesantes de discrepancia entre las normas lingüísticas de ambas ciudades.

\section{Edad senil}

\section{V.1. Corpus de investigación: corpus léxico de ambas ciudades}

Precisemos en primer lugar, qué entiende el DRAE por senectud:

Senectud (del latín 'senectus-utis') f. edad senil, periodo de la vida que comúnmente empieza a los sesenta años.

Edad senil (del latín 'senilis') adj., perteneciente a los viejos o a la vejez.

Vejez: calidad de viejo. 2. edad senil o senectud.

Veamos a continuación cómo se denomina comúnmente a las personas que alcanzan esta edad:

Viejo-a (del latín vulgar 'vechus' por 'vetulus') adj., dícese de la persona de mucha edad (u.t.c.s.) 2. persona que ya no es joven.

Anciano (del latín 'antianus' de 'ante') adj., dícese del hombre o mujer que tiene muchos años y de lo que es propio de tales personas.

\section{2. Análisis semántico contextual y sociolingüístico del corpus léxico}

\section{2.1. VIEJO-A}

Por lo general, este término se adecua al valor asignado por el DRAE: «persona de mucha edad»; podemos citar algún ejemplo: enc. XIV de Sevilla, pág. 531: «los pobres viejos» ${ }^{43}$.

Sin embargo, es frecuente que el hablante haga valoraciones subjetivas aplicando el término a personas que, en sentido estricto, aún no son viejas. En realidad, podríamos encuadrar estas valoraciones dentro de la acepción 2 del DRAE: «persona que ya no es joven»; tal sería el caso de la m. IV en Méjico, pág. 57: «lo veía tan viejo» (hombre de 30 años desde la perspectiva de una adolescente) ${ }^{44}$.

No obstante, debemos constatar que en Ciudad de Méjico el término llega incluso a aplicarse a personas que se hallan en plena juventud: m. III, pág. 41: «ya me estoy haciendo vieja» (es, quizá, el uso más anacrónico recogido en el total de las encuestas; la informante es una joven de ¡19 años! $)^{45}$.

\footnotetext{
${ }^{43}$ Vid. nota 41.

${ }^{44}$ Vid. nota 42.

${ }^{45}$ Vid. nota 43.
} 
De los ejemplos citados, podemos llegar a la conclusión de que el valor común asignado en Méjico al término ‘viejo' es el de «no joven», y no necesariamente «viejo» en sentido estricto. Aún dentro de esta catalogación, hemos observado usos altamente subjetivos que responden a factores sociológicos determinados que apuntaremos más adelante.

Porotra parte, a veces 'viejo-a' sirve para designarun parentescofamiliar; en Sevilla, generalmente a los padres ${ }^{46}$; en Méjico suele hacer referencia a las esposas:m.XIV, pág. 196: «no le hace falta nada a mi vieja» ${ }^{47}$.

Analicemos en un gráfico el porcentaje que representan los diferentes valores del término en una y otra ciudad:

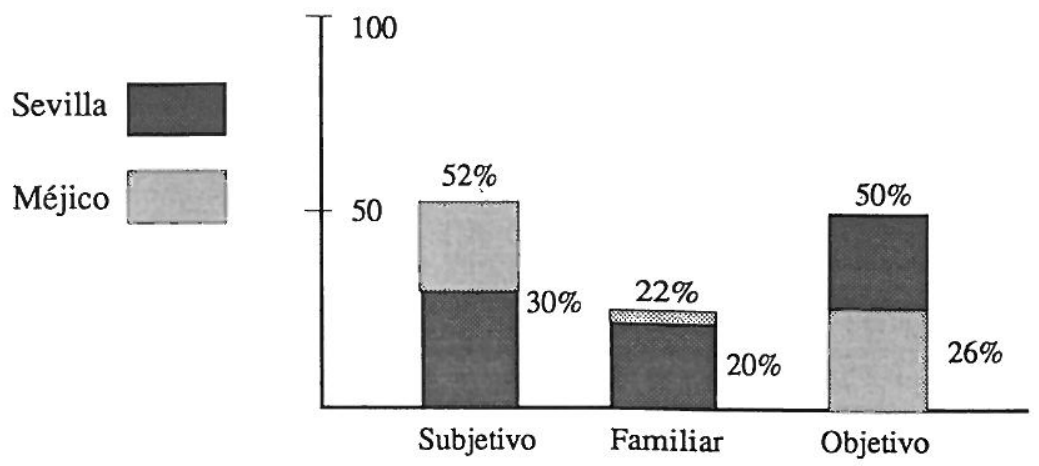

Destacamos el mayor uso del valor subjetivo por parte de los hablantes mejicanos, lo cual lparece indicar cierta conciencia de vejez prematura.

\section{2.2. ANCIANO-A}

Término escasamente usado en las encuestas. Tan sólo recogemos un ejemplo en Sevilla, respondiendo a la acepción del DRAE: enc. VIII, págs. 190 y 198.

\section{Conclusiones}

1. Las denominaciones de la edad por parte del hablante no siempre responden a las acepciones principales del DRAE. siendo determinantes, con frecuencia, las valoraciones subjetivas y la realidad particular del hablante en cuestión.

2. La edad y el sexo de los informantes puede influir directamente en el mayor o menor empleo de un término (como hemos visto al tratar 'chaval', 'chiquillo' y 'chamaco').

\footnotetext{
${ }^{46}$ Vid. nota 44.

${ }^{47}$ Vid. nota 45 .
} 
3. Son frecuentes las ocasiones en que los términos designan relaciones de parentesco familiar. Esto es especialmente relevante en la denominación de los hijos ('niño', 'muchacho'), aunque también hemos podido observarlo en relación a otros parentescos: padre, madre ('viejo-a'), hermanos, nietos ('niño', 'muchacho'), e, incluso, para referirse a la esposa ('vieja').

4. El mayor o menor aceleramiento en las etapas de la vida de los hablantes determina la conciencia lingüística de éstos:

En Méjico deja pronto de usarse la denominación 'niño'; el término 'muchacho' se aplica desde la pubertad, y aún antes; hay personas muy jóvenes que no se consideran tales; hay conciencia de vejez a edades prematuras.

En Sevilla, en cambio, 'niño' se extiende hasta la adolescencia, y aún hasta la juventud; 'muchacho' suele designar a los jóvenes de edades comprendidas entre los 1830; la conciencia de juventud es más amplia; las valoraciones de vejez anticipadas son menos frecuentes.

5. No todos los términos aparecen en ambas ciudades. Tenemos los casos de 'críoa' y 'pequeño-a', no documentados en las encuestas de Méjico, así como el empleo de americanismos desconocidos en Sevilla ('escuincle-a' y 'chamaco-a').

Por otra parte, hay términos que, aunque sean comunes a ambas normas lingüísticas, presentan usos diferentes al aparecer en contextos también diferentes (como hemos podido observar al contrastar los respectivos valores de 'mayor' y 'grande').

Así mismo, se registran ejemplos de total correspondencia, pudiendo sostenerse, en tales casos, que la norma sevillana ha influido, manifiestamente en la mejicana (lo que es especialmente relevante con el término 'chico-a').

6. Aún dentro de ciertas tendencias afines, las encuestas manifiestan una diferente conciencia lingüística a la hora de emplear los términos. Posiblemente, los motivos sean de índole sociológica. En Méjico se observa un aceleramiento general de las distintas etapas de la vida: muchos hablantes han trabajado desde niños; los jóvenes se casan a edades muy tempranas -incuso en la adolescencia-; las condiciones de vida, frecuentemente duras, llegan a producir un desgaste y envejecimiento prematuro. Todo ello repercute en que las denominaciones de las edades se anticipen respecto a Sevilla, donde, por otro lado, las condiciones de vida, tanto a nivel cultural como económico, parecen ser visiblemente superiores.

Creemos que estos factores sociológicos pueden ser determinantes a la hora de explicar las posibles discrepancias entre ambas normas lingüísticas en un ámbito tan personal y subjetivo como es el área léxica de la edad.

\section{Apéndice de notas}

1. Queremos puntualizar que el estudio de estos términos se basa en el cómputo de las encuestas del habla popular llevadas a cabo por las Universidades de ambas ciudades y cuya reseña figura a continuación en las Fuentes Documentales.

2. Hacemos referencia a las páginas de las ediciones mencionadas en las Fuentes Documentales. 
3. Otros ejemplos: -Sevilla: enc. II. pág. 63; enc. VI, pág. 141.

-Méjico: m. II, pág. 36; m. III, págs. 44 y 46.

4. Otros ejemplos: -Sevilla: enc. X, págs. 231 y 232; enc. XII, pág. 316.

-Méjico: m. V, págs. 68 y 70; m. VIII, pág. 117.'

5. Ejemplos: $\quad$-Sevilla: enc. VI, pág. 151.

-Méjico: m. V. pág. 54; m. XIX, pág. 264.

6. Otros ejemplos de Sevilla: enc. III, pág. 90; enc. V, págs. 131 y 133: enc. X, pág. 230; enc. XIV, pág. 328.

7. Ejemplos de Méjico: m. I, pág. 22; m. V, pág. 75; m.XI, pág. 153; m. XVIII, pág. 261.

8. Otros ejemplos: $\quad$-Sevilla: enc. III, pág. 89; enc. XI, págs. 255, 259 y 271; enc. XVI, pág. 360.

-Méjico: m. XXVI, pág. 347.

9. Otros ejemplos: enc. XIII, pág. 318; enc. XV, pág. 352.

10. Otros ejemplos: enc. VI, pág. 151; enc. VIII, pág. 191; enc. XX, pág. 455.

11. Otros ejemplos: -Méjico: m. IV, pág. 50.

-Sevilla: enc. VI, pág. 148; enc.XVI, pág. 363.

12. Ejemplos: $\quad$-Sevilla: enc. XXI, pág. 464; enc. XXIII, pág. 512.

-Méjico: m. VII, pág. 104.

13. Ejemplos: enc. VI, pág. 143; enc. X, pág. 247.

14. Otros ejemplos: -Méjico: m. IV, pág. 60.

-Sevilla: enc. XX, pág. 443; enc. X, pág. 232.

15. Ejemplos: m. VII, pág. 103; m. XIX, pág. 265.

16. Otros ejemplos: m. XIV, pág. 187; m. XXIV, pág. 337; m. XXIV, págs. 338 y 340 .

17. Ejemplos: $\quad$-Sevilla: enc. VIII, pág. 189; enc. XIX, pág. 470.

-Méjico: m. XX, pág. 239; m. XIV, pág. 195.

18. Otros ejemplos: enc. XXII, pág. 504; enc. XXI, pág. 407.

19. Otros ejemplos: m. VII, págs. 94 y 104; m. X, pág. 138.

20. Otros ejemplos: -Sevilla: enc. XXIV, pág. 533.

-Méjico: m. V, pág. 72.

21. Salvo un ejemplo que designa a un niño mediante el empleo de diminutivo; m. XXVIII, pág. 371: «tu chavito».

22. Otro ejemplo: -Sevilla: enc. VII, pág. 168; enc. XVIII, pág. 393.

-Méjico: m. XIX, pág. 263; m. XXI, pág. 287.

23. Ejemplos:

-Sevilla: enc. VII, pág. 168; enc. XVIII, pág. 393.

-Méjico: m. XIX, pág. 263; m. XXI, pág. 287.

24. Otros ejemplos: -Sevilla: enc. XIII, págs. 309 y 310; enc. XIX, pág. 419.

-Méjico: m. XV, pág. 206; m. XII, pág. 172.

25. Ejemplos: enc. IX, pág. 237; enc. VIII, pág. 198.

26. Ejemplos:

-Sevilla: enc. III, págs. 33 y 35.

-Méjico, m. IX, pág. 120.

27. Otros ejemplos: $\quad$-Sevilla: enc. XIV, pág. 352; enc. XIII, pág. 320.

-Méjico: m. XIV, pág. 200; m. XXIII, pág. 309. 
28. Ejemplos:

-Sevilla: enc. XII, pág. 296; enc. XIII, pág. 317. -Méjico: m. XIII, pág. 177; m. XIV, pág. 194.

29. Ejemplos:

-Sevilla: enc. II, págs. 48, 52 y 53; enc. VIII, pág. 197. -Méjico: m. VI, pág. 77; m. XIII, pág. 174.

30. Otros ejemplos: -Sevilla: enc. VI, pág. 155; enc. X, pág. 233.

-Méjico: m. IV, pág. 60; m. VII, pág. 104.

31. Otros ejemplos: enc. XII, pág. 296; enc. V, pág. 131; enc. XVI, pág. 360.

32. Otro ejemplo: enc. XXI, pág. 473.

33. Otro ejemplo: enc. X, pág. 233.

34. Otros ejemplos: enc. XVI, pág. 364; enc. XIII, pág. 312.

35. Con esta afirmación rectificamos la no consideración del valor positivo del término «grande» en la ciudad de Sevilla en nuestro artículo citado (vid. I. objetivo del trabajo) tras haber sido documentado un ejemplo en el material de las encuestas: enc. XIV, pág. 333: «mi niño está grande». Observamos que el término está empleado con valor subjetivo y relativo a la situación contextual: el pequeño de ocho meses permite ya salir con él.

Insistimos, sin embargo, en el escaso uso del término entre los hablantes sevillanos, tanto con valor comparativo, como positivo, ya que, en realidad, solo aparece documentado en una informante.

36. Otros ejemplos: m. VIII, pág. 118; m. XIII, pág. 170; m. XIV, pág. 195.

37. Otros ejemplos: m. XVIII, pág. 263; m. IX, pág. 125; m. XIV, pág. 194.

38. Otro ejemplo: m. XIII, pág. 170.

39. Otro ejemplo: m. XIV, pág. 197.

40. Otros ejemplos: m. VII, pág. 105; m. XVIII, pág. 254.

41. Otros ejemplos: -Sevilla: enc. II, pág. 62; enc. VIII, pág. 197.

-Méjico: m. XIII, pág. 172; m. XXI, pág. 293.

42. Otros ejemplos: -Sevilla: enc. X, pág. 241; enc. XXIV, pág. 531.

-Méjico: m. VII, pág. 106; m. XIX, pág. 262; m. XXX, pág. 412

43. Otros ejemplos: m. XVIII, pág. 254; m. VII, pág. 106; m. XIX, pág. 262;

m. XXX, pág. 412.

44. Otros ejemplos: enc. IX, págs. 206 y 224.

45. Otro ejemplo: $m$. V, pág. 60 . También encontramos un caso de referencia a las hermanas mayores: m. XIX, pág. 262.

\section{Fuentes documentales}

- LOPE BLANCH, J. Manuel ed., El habla popular de la ciudad de Méjico, U.N.A.M., Centro de Linguiística Hispánica, 1976.

-ROPERO NÚÑEZ, Miguel ed. Sociolingüística andaluza, vol.IV. Encuestas del habla urbana de Sevilla -nivel popular-. Publicaciones de la Universidad de Sevilla, 1987. 


\section{Bibliografía utilizada}

- REAL ACADEMIA ESPAÑOLA. Diccionario de la lengua española. $20^{\mathbf{a}}$ ed. Ed. Espasa Calpe S.A., 1984.

-SANTAMARÍA, F. Javier, Diccionario general de Americanismos. Méjico, ed. Pedro Robrado, 1942. 